\title{
The narratives of fertility clinic's websites in Spain
}

\author{
Leila Mohammadi; Daniel Aranda; Silvia Martínez-Martínez
}

How to cite this article:

Mohammadi, Leila; Aranda, Daniel; Martínez-Martínez, Silvia (2019). “The narratives of fertility clinic's websites in Spain". El profesional de la información, v. 28, n. 2, e280219.

https://doi.org/10.3145/epi.2019.mar.19

Article received on November, $9^{\text {th }} 2018$ Approved on March, $1^{\text {st }} 2019$

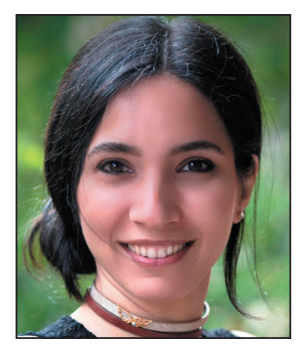

Leila Mohammadi $\triangle$ https://orcid.org/0000-0001-9090-2427

Universitat Oberta de Catalunya Estudis de Ciències de la Informació i de la Comunicació

Av. Tibidabo, 39-43. 08035 Barcelona, Spain limohammadi@uoc.edu

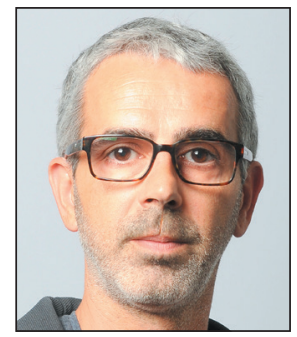

Daniel Aranda

https://orcid.org/0000-0001-9290-0708

Universitat Oberta de Catalunya

Estudis de Ciències de la Informació i de la Comunicació

Av. Tibidabo, 39-43. 08035 Barcelona, Spain darandaj@uoc.edu

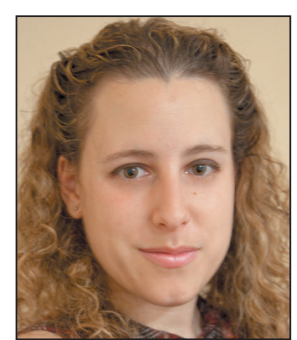

\section{Silvia Martínez-Martínez}

https://orcid.org/0000-0002-6666-7954

Universitat Oberta de Catalunya

Estudis de Ciències de la Informació i de la

Comunicació

Av. Tibidabo, 39-43. 08035 Barcelona, Spain

smartinezmartinez1@uoc.edu

\begin{abstract}
One of the important developments in assisted reproductive technology is the technique of oocyte preservation, which enables women to preserve their eggs when there is a threat of becoming infertile in the future. In spite of the still experimental status of this procedure, fertility clinics widely recommend it to healthy women who wish to postpone childbearing for social reasons. Since in fertility clinic's websites appear extensive recommendations and promotion about this technology, it seems important to analyze their online persuasive communication. Our analysis applies a mixed methodology of content and discourse analysis from a framing theory perspective. It provides an in-depth analysis of the content of fertility clinics' websites in Spain, describing their communication/information strategies regarding fertility preservation for social reasons. The present article confirms the inconsistency that exists in terms of the clarity of the information given by these websites, since the information is framed intending to attract more women to the egg freezing services.
\end{abstract}

\section{Keywords}

Framing theory; Persuasive communication; Content analysis; Social egg freezing; Fertility clinic's website; Clinics; Oocyte cryopreservation; Freedom of women; Health information; Reproductive autonomy; Maternity; Rhetoric of choice; Women's liberation; Information quality; Delayed childbearing; Fertility preservation.

\section{Introduction}

In the last decades there has been a rise in the age at which women have their first child worldwide, while the number of children born per woman has been decreasing (Statista, 2018). For instance, in the UK, this age rose from 28.5 in 2000 to 34.5 in 2016 (Office for National Statistics, 2017). In Spain, the number of children has decreased to 1.2 per woman, while the age of the first birth has been rising from 30 in 2005 to 32.5 years old in 2016 (Eurostat, 2018; INE, 2017).

The availability of contraceptive methods provided women the opportunity of avoiding undesired pregnancy and choose between motherhood and other opportunities like education 
The oral contraceptive 'pill' and other reliable contraceptive methods have enabled women to control their own reproduction (Bailey, 2006). The availability of contraceptive methods provided women the opportunity of avoiding undesired pregnancy and choose between motherhood and other opportunities like education (Goldin, 2006).

The improvement of assisted reproductive technology is also one of the important reasons of the delay in the age at which women give her first birth (Shaw; Giles, 2009). One of the important developments of assisted reproductive technology is the technique of oocyte preservation, so-called egg freezing, which was developed in the late 1980s. This technology enables women to preserve a number of healthy eggs when there exists the threat of becoming infertile, caused by medical difficulties or a medical treatment. For instance, it allows women who have been diagnosed with cancer, when the quality of their eggs decreases after taking a chemotherapy treatment, to use their eggs before undergoing treatment (Rienzi et al., 2004; Stoop et al., 2015). However, after a short while, this technology started to be offered to healthy women as well, who wish to defer childbearing for social reasons (Baldwin, 2016).

In spite of the still experimental status of the egg freezing procedure, fertility clinics widely recommend it to healthy women who wish to postpone childbearing, as a solution to avoid infertility issues that may arise in the future (Harwood, 2009; Koert; Daniluk, 2017). Since the success rate of this process is low, it is very possible that it won't fulfill women's expectations (Meyer, 2015). Therefore, considering the growth in the number of women undergoing egg freezing for social reasons (Press Association, 2016; Donnelly, 2016), it is possible for them to become traumatized, which might affect their personal and, consequently, social life (Vallejo et al., 2003).

In the past few years we see a growth in health-related websites and in the number of users who seek health information from professionals as well as others experiences in the websites, blogs, social networks, forums, etc. (Newhouse, 2015). One of the most used tools for health communication especially for private clinics is websites to promote their health-related service (Kline, 2006). Websites are essential sources of information for fertility clinics and many people go online into websites to obtain the information that they need (Murray et al., 2003).

There have been a lot of studies assessing the information related to health issues that are given through the media (Kline, 2006). Researchers have explored the quality of the information and its impact on the people who need this information through websites, TV, advertising and printed media and magazines (Wilkinson; Vail; Roberts 2017; Eysenbach et al., 2002; Smith et al., 1972; Mittal, 1994; Moyer; Vishnu; Sonnad, 2001). These issues have been studied applying various methods of research and from many different perspectives.

Since in fertility clinic's websites appear extensive recommendations and promotion about social egg freezing, it seems important to analyze the strategies applied by fertility clinics to persuade women that are taking this technology through their online communication. In this article we will use a framing theory perspective to analyze those websites. It means they will be examined to see what kinds of framing have been applied to the content.

\section{Explanatory theoretical background: Framing theory}

Framing theory originally belongs to psychology science (Bartlett, 1932) which got involved in the field of communication to help uncover the keys of media policy (e.g., Tuchman, 1978), to understand the way in which media "frame" the topics that lead the audience's attention to certain features of the subject, or determine interpretations which are far from other alternative interpretations (Shaw; Giles, 2009).

Framing theory has an interdisciplinary nature (Entman, 1993) applied in various fields from psychology to marketing. There are studies of framing used to describe marketing and advertising, which include analyzing whether a product is framed based on price versus benefits (Smith; Wortzel, 1997).

D’Angelo (2002) states that the framing theory is a combination of the cognitive, constructivist, and critical perspectives. For him, the cognitive perspective receives the most emphasis in communication research on media effects. Reese et al. (2001) focuses mostly on critical perspectives. He states critical perspectives open up new questions to the media studies, and consequently give significant value to what used to be called unscientific critical theory. For instance, frames can give meaning and definition to social concepts and make them coherent (Reese, 2001). They are central ideas, which relate events to make them significant; and they do so in a format which expresses ideas metaphorically using catchphrases, stereotypes, or symbolic images proficiently (Gamson, 1989). Frames tend to highlight the concept, which needs to be reinforced in the content. Communicators have done this either consciously or unconsciously (Entman, 1993).

Hence, to analyze frames, the central concepts need to be identified to recognize the main narratives (Gamson, 1989), which is possible to do through content analysis and discourse analysis. 


\subsection{Content and discourse analysis}

According to Holsti (1969), content analysis refers to

"any technique for making inferences by objectively and systematically identifying specified characteristics of messages" (Holsti, 1969).

Content analysis as a systematic technique to categorize and organize a text based on a specific codification (Weber, 1990) can be used to summarize the text, which enables researchers to detect and describe the central point of the individual, institutional, or social attention (Weber, 1990). It can also be used to make inferences out of the context, which can be supported using other methods. In this article, content analysis and discourse analysis complemented each other and provided a qualitative description of the subject of the research.

This article approaches discourse analysis methodology attempting to make a connection to textual communication and society. It uses that process to understand the phenomenon embedded in the texts, images, messages and link it with the representations of the social world.

Discourse analysis has been applied in various ways, from linguistic researches to the philosophical approaches. According to Van-Dijk (2013), in discourse analysis the discourses are analyzed from two dimensions: textual and contextual. The textual dimension deals with the main structure of the discourse, such as texts, images, talks, conversation, etc., while the contextual one deals with linking these structures and their representations of the social world, such as the cultural context in which a conversation can make sense (Van-Dijk, 2013).

So, for the textual dimension, elements like the structure of subjects, phrases, titles as well as rhetorical devices, syntax, intonations, meanings, metaphors, and for the contextual dimension, the process in which the discourse structure is made, the process in which it will be received by the audience and how they are related to the social world and situations, are the main elements to be analyzed (Van-Dijk, 2013).

In discourse analysis, unlike content analysis, the focus is not on analyzing the message. It emphasizes the ideologies that are linked to the process of creating the discourses (Wolf, 1988).

In media discourse analysis, normally, both discourse production and reception by the audience is analyzed critically. So, it is essential that claims are logical and well-articulated. According to Potter \& Wetherell, there are some principles in discourse analysis that can show its validity. He states that the analysis structure should be reasonable to make it effective.

It is necessary that the raw textual material appears in the analysis. This enables other researchers to see the process of analysis and follow the logic of the author. The analytical process should be logical and well explained in order to make the process understandable for others. Claims should be well articulated since they are the links to find the patterns, and finally, discourse analysis should cover a critical dimension other than observing the content and describe it (Potter; Wetherell, 1987).

In most of the cases, media, production of discourse and its reception by the audience are examined critically and not just descriptively. Discourse analysis is an adequate way to understand the communication process as well as messages and their meaning.

Therefore, in order to have a deep insight into fertility clinics communications in their websites, discourse analysis has been applied. This methodology provides an insight to the relationship between women, society, social beliefs, providers, and communication strategies through which information is presented and meanings embedded within the context of the websites of fertility clinics related to social egg freezing.

\section{Method and analytical procedure}

Our sampling procedure started by selecting the first 50 appeared in Whatclinic.com, which is one of the most reliable websites to find health centers. To avoid biased sampling, we put together these 50 clinics with other 50 fertility clinics that appeared in a search process through Google.com excluding the advertising. After comparing these two groups of 50 fertility clinics, 28 of them, which have appeared in both Google.com and Whatclinic.com, were selected. Next, their websites have been checked and 9 fertility clinics were eliminated since they didn't provide the service of "Fertility preservation" which also is called as "Egg freezing" or "Oocyte freezing" in their websites. Finally, 19 fertility clinics' websites, which offer fertility preservation for women, have been selected (see Annex). 
These 19 clinics are all private, while they have different scales and presences. The majority of them are single clinics, or they have few centers while some of them have many centers. For example, Instituto Valenciano de Infertilidad (IVI) has 35 centers in Spain and 11 in other countries; Hospital Quirón has centers in almost all of the cities in Spain. However, some of these clinics such as García de Real (URH) and Instituto Europeo de Fertilidad have just one single center.

Each website comprises many pages, among which the homepage plus an average of three pages deal with fertility preservation treatment. The entire content of the pages, which dealt with fertility preservation, was downloaded and collected as the sample of our study.

Content analysis and discourse analysis have been performed in our study. These analyses have been done from a framing theory perspective. The progress included various stages, which helped us to do a systematic analysis.

First, a content analysis has been applied to identify two narratives that have been deduced as the main inferences through which all the identified frames have been explained. These two narratives were identified as "Promoting the clinic" and "Persuasive communication of egg freezing technology".

For coding the first narrative, promoting the clinic, a review revealed the presence of four components of the mix marketing model so-called McCarthy's 4 Ps (Blythe, 2009), which means: their information is ordered following the presentation of the product, price, promotion, and place as it is shown in Table 1.

Table 1. Frames, codes and examples of narrative 1

\begin{tabular}{|c|c|c|}
\hline Frames & Codes & Examples of terms \\
\hline Product & Clinics characteristics & $\begin{array}{l}\text { - The best specialists in reproductive medicine } \\
\text { - In house laboratory and specialized technology } \\
\text { - No waiting lists } \\
\text { - Third person testimony (articles, comments, forums, etc.) } \\
\text { - Success rate }\end{array}$ \\
\hline Price & Cost & $\begin{array}{l}\text { - ... no need to waste the time trying different options... } \\
\text { - Price list, discounts }\end{array}$ \\
\hline Promotion & Advertising and sales promotion & - So that nothing stops you, we finance the cost of your treatment, etc. \\
\hline Place & $\begin{array}{l}\text { Physical place and communication } \\
\text { channels }\end{array}$ & $\begin{array}{l}\text { - The expertise of one of the biggest fertility groups in the world, with } 50 \text { clinics in } 11 \\
\text { countries } \\
\text { - An atmosphere of warmth and quality in our clinics and laboratories } \\
\text { - Social networks links }\end{array}$ \\
\hline
\end{tabular}

For the second narrative, a range of possible frames have been made explicit and they were set in a list. Then keywords were developed and finally, the content has been coded and categorized. Codes were created by frequencies observed through an inductive method. We identified five frames with their respective codes, as we see in Table 2.

Table 2. Frames, codes and examples of narrative 2

\begin{tabular}{|l|l|l|}
\hline \multicolumn{1}{|c|}{ Frames } & \multicolumn{1}{c|}{ Codes } & \multicolumn{1}{c|}{ Examples of terms } \\
\hline Fertility preservation & Freedom & Fertility preservation, maternity preservation, etc. \\
\hline Have it all & Control & ...Who wants to postpone the maternity with guarantee... \\
\hline Delay motherhood for social reasons & Social pressure & Delay for various personal or social reasons \\
\hline Being mother whenever you wish & Choice & Postpone the maternity for those women who wish to do so \\
\hline Success rate & Success & $90 \%$ \\
\hline
\end{tabular}

\section{Results and discussion}

In our analysis, we looked at the homepages of the clinic's website as well as pages related to egg freezing treatment. Each website includes an average of three pages associated with our subject, and they were observed deeply. A range of possible frames has been denoted and studied. Considering that even doctors working in fertility clinics recognize that clinics promote their services using the information on websites (Jain; Barbieri, 2005) we consider all the statements as a framed statement.

Next, the coding process has been applied to our data. As we mentioned earlier, all the framed statements were coded and categorized in two main narratives called "Promoting the clinic" and "persuasive communication of egg freezing technology". 


\subsection{Narrative one: Promoting the clinic}

\subsubsection{Description of narrative one}

During the process of analyzing the clinics' websites, we discovered that they have different patterns, but most of them include colorful photos of babies, women, family, and doctors, and information related to the clinic itself and its treatment services. More extensive information about fertility preservation can often be found in the treatment sections. In the page of fertility preservation, normally, the most visible and frequent link is to "set your free appointment" for consultancy. There are also other links to pages such as "calculate your fertility" or "calculate your oocytes quality", information about the process, success rate, price, videos and photos, articles and blogs.

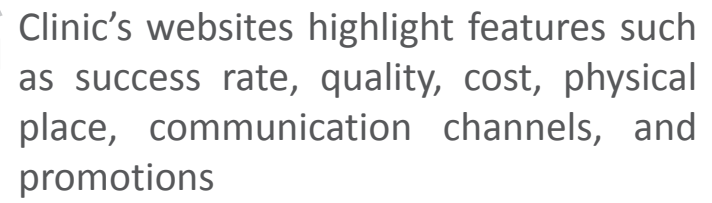

The most highlighted characteristics of these websites show the perception of clinics about key elements that matter to people, in terms of taking a rational decision about choosing a clinic. These elements were clinics' features such as success rate, quality, cost, physical place, communication channels, and promotions.

There might be multiple reasons behind the given information. They might provide essential information about the clinic as well as its treatments or they may simply be the clinics' attempts to frame the interaction in a way that attracts women to the clinic. The frames that clinics choose to communicate demonstrate the important dimensions people care about when they choose a fertility clinic.

\subsubsection{Rational based framing: Identified frames meeting the mix marketing model}

As it has been mentioned earlier, we categorized all the statements into four categories:

- clinic characteristics;

- cost;

- physical place and communication channels ;

- advertising and sales promotions.

The categorization we have obtained showed a conformance to the mix marketing model. Since this model aims to pursue its marketing objectives in regards to the target (Kotler, 2000), marketing based frames were detected in these websites.

Marketing mix refers to four levels of marketing decision: product (service), price, promotion, and place.

\section{1) Product}

Refers to what the business offers for sale and in our case of study, the clinic itself is the product. Our analysis shows that the information about the clinic includes quality, benefits, branding, service, and warranties. Table 3 shows some examples of framed phrases appearing on the websites, being related to the features of the clinic.

Table 3. Fertility clinic characteristics according to mix marketing model

\begin{tabular}{|c|c|}
\hline Clinic characteristics & Examples of framed phrases in the content \\
\hline Quality & $\begin{array}{l}\text { - The best specialists in reproductive medicine } \\
\text { - Specialized technology } \\
\text { - Excellent success pregnancy rates } \\
\text { - Competitive fees } \\
\text { - Clinic's previous experience }\end{array}$ \\
\hline Benefits & $\begin{array}{l}\text { - No waiting lists } \\
\text { - In-house laboratory }\end{array}$ \\
\hline Branding & $\begin{array}{l}\text { - World leading fertility group } \\
\text { - Our clinic stories } \\
\text { - 160,000 happy ending stories }\end{array}$ \\
\hline Services & $\begin{array}{l}\text { - Personal patient care assistant to guide you through your treatment } \\
\text { - Personalized medical care in your own language } \\
\text { - Rigorous follow-up by the whole medical team }\end{array}$ \\
\hline Warranties & $\begin{array}{l}\text { - Committed to continuous global investment into our clinical medical technology, laboratories and equipment } \\
\text { - Achieving high rates of success } \\
\text { - Ensuring that all our patients receive the best possible } \\
\text { - Testimony (articles, comments, forums...) }\end{array}$ \\
\hline
\end{tabular}

\section{2) Price}

The second and the most important " $P$ " in the marketing mix model is "Price" which refers to the cost of achieving a wish, including the cost of time or even the conscious decision (Kotler; Keller, 2006). In these websites, different stra- 
tegies regarding how the price is presented have been shown including detailed price presentation or a link that allows you to send an email to "ask for price information". In all the cases the intention to show the price and explain its logic and how worthy it is in relation to what clients obtain, is central and key.

\section{Clinics offer loans, financing for the cost of the treatment, discounts on private} insurance, etc.

\section{3) Promotion}

Any communication whose aim is to create a dialogue with the potential clients based on the offered product or service. It includes elements such as advertising, public relations, sales promotions, etc. Loans offered by clinics, financing for the cost of the treatment, discounts on private insurance ads, etc., are some examples that demonstrate how promotions appear in these websites: (e.g., "...So that nothing stops you, we finance the cost of your treatment").

\section{4) Place}

Can be defined as both physical location and communication channels to market in order to guarantee convenience. In our study, the easy accessibility of locations and number of branches are presented "e.g., we have 26 clinics all over the world..., an excellent residency area." Regarding communication channels, there are always links to various social networks such as Facebook, Twitter, Instagram, YouTube, Google+, Pinterest, etc. In this digital age we can consider those social networks as their main channels to market.

\subsection{Narrative two: persuasive communication of egg freezing technology}

\subsubsection{Description of narrative two}

These websites have different ways to present information about egg freezing technology but most of them communicate emotionally rather than rationally. Presenting images of happy or successful women could have different kinds of impact on women. Women could disregard the risks in light of the value of solving a bigger problem. It is possible that women will be reluctant to value their satisfaction with the cost of the treatment, and that they may pay no attention to the price.

Given that undergoing this procedure is very expensive, the price may be one of the most important issues that women deal with. Placing the focus on a grey picture of a clock, showing the time limitation, on the body of a woman, may communicate the necessity of buying time at any price.

Since many of these images show the outcome of the treatment, a successful woman who can manage her social and personal life equally, they may push women to draw their own conclusions, and this could be more persuasive than direct claims or even verbal metaphors (Goldman; Tushnet, 2014). Thus, it is not surprising if these images are even more persuasive than the success rates that appear frequently in these web pages. That shows that these frames that fertility clinics use to showcase their high success rates are subtle and powerful.

Videos are another component of the content of these websites. They include interviews with women who speak about their experiences when undergoing this procedure. The content might be persuasive since they look satisfied by what they have done, and how they solved the problem of limited fertility time combined with the social challenges that every woman may face in her life. For example, Alicia 42 years old, who has frozen her eggs at her 38 says:

"...I did a lot of research. The success rate is not so high and I knew that at my age is max $20 \%$ per cycle, but still it is still, pretty high... compared to not being able to have a baby in the future."

Going more in depth, we found that the main frame in their speeches is the choice that should be taken. They speak about their choices and their consequences. The benefits of choosing to do the treatment are highlighted in their speech. They consider themselves autonomous and independent in regards to their biological limitations, so that less pressure is felt on their lives and more success can be achieved.

Scholars believe that framing in terms of choice can be a very persuasive and powerful tool to convince women, since it does not convey any obligation neither looks like an advertisement. However, there is always another choice if you don't like this one (Gill, 2007; Greenfield, 2009).

Two possible choices are highlighted in these videos. First one is to freeze the eggs since that is a way to decrease potential concerns about age-related fertility limits and enables women to have more freedom to take a decision about childbearing even if they never need to use them. The second is not choosing that first option. In that case, they may regret that decision in the future when it is already too late.

Maria, 39 years old, is in the process of doing her second eggs retrieval says: 
“...all my friends have kids... I am not in a position in my life, in my career and in my relationship to be able to have children. ... I want to be sure that I would not feel anxious in the future about not being able to have kids. I don't know if I want to have kids or not but I don't wanna miss out on that chance... I know women rushing into relationships having kids with a partner who is not the right one, so that the relationship does not work and they have to deal with being a single mom... I know also women meeting the love of their lives in their late 30s or early 40 s and then they realize that it is going to be a real challenge having kids."

Ana, 37 years old says:

"I didn't wanna be dependent on my biological limitations. If I can do something to feel less pressure in my life, then why not? I didn't wanna end up childless just for being too late. There wasn't another alternative... I froze my eggs two years ago and since then I feel less rush in my life..."

Many studies have argued their perspective about "choice" in relation to women's experiences. The idea originally comes from theories on individual rights and autonomy, which have been addressed by women during decades with the purpose of creating their own destiny, including employment decisions, childcare, breastfeeding and motherhood (Teghtsoonian, 1996; McDonald; Bradley; Guthrie, 2006; Hausman, 2008; Hayden; O’Brien-Hallstein, 2010).

McCarver (2011) states that in cultural narratives making a choice personally is the symbol of an individual's autonomy and being the owner of one's own life. Women are proud to use the rhetoric "choice" to manifest their self-perceived status as an independent and autonomous being who is not restricted by gender constraints (McCarver, 2011).

Further, our analysis identified a variety of frames in the context of these pages. The following concepts are the most frequent ones that have been noted in these web pages. That means that the following terms and phrases and their synonyms were the main frames used by fertility clinics to market egg freezing technology.

\subsubsection{Emotional based framing: Identified frames meeting sociocultural scenarios}

\section{Fertility preservation}

Fertility preservation, so-called "egg freezing", "maternity preservation" or "oocyte cryopreservation" is the title of the treatment in most of the websites, and the most frequently used term in the context of these pages, which can imply many concepts. The main idea of this frame is to convey that social egg freezing provides women reproductive freedom or fertility insurance.

From a lexical point of view, preservation, from one side, in general, is a positive concept, and when it is about preserving an ability is a gain-framed message, which creates the feeling of considering it as a chance or a right decision to make. From the other side using the term "preserve" implies the concept of limited time. In other words, it means that there is an expiration date for the reproductive life cycle that needs to be stopped or extended.

\section{Have it all}

According to Inhorn (2013) studies that have been done about egg freezing, assert that the reproductive freedom provided by this technology is a feminism "game changer" since it allows women to not feel forced to choose either motherhood or career.
The rhetoric of "have it all" is a powerful frame which gives the feeling of being able to overcome all the limitations by circumventing biological limitations

The rhetoric of "have it all" is a powerful frame which gives the feeling of being able to overcome all the limitations by circumventing biological limitations (Harwood, 2009; Richards, 2013; Urist, 2013). Although the rhetoric of "have it all" oversimplifies the real-world challenges, and social egg freezing does not guarantee that we can "have it all" this rhetoric makes it all seem possible and safe for women (Cattapan et al., 2014). One example, which aims to assure women that they can have it all, is: "...Women can already dodge their biological clock and postpone the moment of being mothers without risking fertility problems."

This frame of "having it all" and the way it is offered emphasizes that all the responsibility falls on women, in regards to childbearing or planning to have children. So all that matters is the time available and if the woman has the possibility of freezing her eggs, it's better to do that, otherwise they are the only responsible beings for not being able to be a mother later, and any negative consequences associated in terms of small physical problems that make the process fail, are again her fault since she wishes to have it all.

The frame of "having it all" stems from the old story in which childless women were not accepted culturally in society

This frame stems from the old story in which childless women were not accepted culturally in society. According to Miall (1985), married women are expected to have children. Besides, since being fertile has been seeing as an ability, not 
having children, desired or not, is seen as a stigma and a disability for them. A lot of researches on disability state that stigma increases when one "become" disabled. Goffman noted that stigma is given to one for having an undesirable condition which is contradictory to what is considered the normal state (Goffman, 2009). Hence, avoiding infertility in order to not feeling stigmatized and isolated from the society, can be a consequence of this structure.

\section{Delay motherhood for social reasons}

An important part of the information gathered in these pages is about "Who can use this technology?" In most of the pages, the first group of women who can freeze their eggs includes women "who wish to delay motherhood for social reasons"; "...personal reasons" or "who are not ready yet". Some of the websites explain it in detail, pointing out reasons such as education, partner status, etc.

For example, one of these pages uses the following text to explain who can make use of the technique of egg freezing:

"Currently, the best reproductive years of women coincide with a stage in her life in which she is still struggling to find her place, both academically and in the labor market. With the arrival of vitrification, women will be able to have children later, with the peace of mind that their children will be born healthy and strong. Egg freezing allows the woman to use her own eggs after a few years without the eggs having aged, and therefore, avoiding losing a lot of quality."

There are some critics of the idea of egg freezing, which suggest that it is an individualist solution to a social issue, and in addition that this is an experimental, expensive and physically psychologically risky procedure for women (Cattapan et al., 2014). Feminism criticizes this idea and they propose a change in social policy alike providing

"paid parental and sick leave, affordable child care, comprehensive health insurance, health care, and adequate payments."

This phrase is framed in a way that intends to block other solutions and make women think that they are the only responsible ones that have to overcome all the obstacles they face in their social life.

The term of "delay" conveys a negative feeling, conveys that a task has not been accomplished on time, so it invokes irresponsibility or in this case selfishness for choosing not to have children at the optimum age so that one feels compelled to find a solution.

\section{Being a mother whenever you wish}

The concept of having the chance of being a mother "Whenever you wish or are ready" personally or socially has been pointed out intensively in these websites. In the kind of phrases they use, the main frame is about the extra time you get to do other activities rather than being a mother. Another example is "What would you do if you had time to realize your dreams?"

These structures carry various implications. The first is that being a mother is inevitable or something mandatory and the only issue that matters is time. Hence being a mother is the destiny of women, but they can choose when they want to fulfill that destiny. The second implication is that there would not be a limitation regarding age in case of using this technology. Using the term "whenever" intends to transmit that undertaking this process is a guaranteed solution that allows women to have unlimited time to make decisions related to their motherhood.

\section{Success rate}

Success rates appear in different forms in these web pages, including: spoken in videos, images, texts including a response to questions posted on frequent questions sections.

Success rates are different in every clinic and for each treatment, but they are usually presented as being very high and not well explained. The success rate related to egg freezing presented in these pages are between $85 \%$ and $90 \%$.

The only complementary description accompanying success rates is a simple short explanation about factors that affect them. The most important factor connected to the success rate, is the age of the woman, which directly affects the quality of eggs. However, this information about success rate is neither clear nor enough for a woman that is going to take the decision to freeze her eggs.

The maximum recommended age to uptake the procedure discussed in some of the pages is simplified to being less than 38 years old, meaning there might be no difference in quality between a 22-year-old egg and a 38-year-old one. There is just one number showing the high success rate which is normally $85 \%$ or higher. This might convey an equal chance of success for all the women less than 38. However according to the Spanish Society of Fertility the success rate of this procedure for a 38-year-old woman is less than $25 \%(S E F, 2016)$.

The other critics to this way of presenting the success rate state that it is not demonstrating the sample. The success rate of a fertility clinic presents the average of each procedure's success rate in which the age of the egg is the most important factor. Since each clinic has different clients with distinct ages, it is impossible to determine a standard rate to make them comparable. In conclusion, these numbers might not be significant, since there are no additional details explaining the calculation process of the success rate that has been carried on by the clinics. For example, a $90 \%$ success rate might be 
calculated considering the results of young women less than 25 years of age, and cannot be the same for a 36-year-old woman. However, as long as women are not given more data regarding this issue, those numbers might make no sense.

According to the explanation presented in these websites, egg freezing is a multi-stage process, which includes ovarian stimulation, egg retrieval, freezing eggs, storage processes and the final stage, which is the fertilization of the eggs using in-vitro fertilization (IVF) or intracytoplasmic sperm injection (ICSI). The success rate shown in these pages might be calculated for one of the above stages except the last stage (IVF/ICSI) which is explained in another page of the clinics. In addition, no clinics reported live birth rates, which are, obviously, the only reason because of which women freeze their eggs.

\section{Success rates given by clinics might make no sense as long as women are not given more data regarding this issue}

\section{Conclusion}

The present paper confirms the inconsistency that exists in terms of the clarity of given information by fertility clinics websites, since the information elements they use are framed intending to attract more women to use the egg freezing services.

Framing theory allowed us to understand the way in which this information is constructed to lead the individual's attention to certain features of the subject and also to determine interpretations. Using framing theory we could give a new definition to the concept which has seen reinforced in the content of fertility clinic's websites. The central idea defined by framing in this study is commercializing the service of egg freezing.

The analysis of the "promoting the clinics" narrative showed an adoption of a marketing model in which all the four components of the model (product, price, promotion, and place) were presented in the construction of the content. That means the content is framed to promote the clinic. The most frequent phrases were framed based on the clinic's features which are embedded in the first element of this model.

However, all these four elements are assumed to be keys for potential clients when it comes to choosing a clinic. Therefore, the main focus of each clinic is to present them as a unique and best solution. Features like high success rate, the excellent quality, the number of branches, the years of experience, competitive prices, and the variety of their services are the most highlighted ones. However, although there are different patterns followed by these clinics, the main aim is the same for all of them, and that is: marketing them.

They are framed to persuade women and without giving any scientific source or any proof explaining the liability of them. For example, asserting to have the highest success rate of egg freezing when it is still complicated to measure it because of lack of a standardized protocol and consequently not being transferable in order to be compared to other centers (Von-Wolff; Germeyer; Nawroth, 2015; Argyle; Harper; Davies, 2016), is not liable. The same defect for the expertness and experience of the clinic and the doctors (Von-Wolff; Germeyer; Nawroth, 2015) can show the inexplicitly of the information. Obviously, comparing their center with others in terms of price and variety of services, while there is no information about the rest, only can be explained in a marketing frame.

The analysis of egg freezing technology marketing allowed us to identify five main frames presented in different phrases in the content of these websites which are

- Fertility preservation;

- Have it all;

- Delay motherhood for social reasons;

- Being a mother whenever you wish;

- Success rate.

These show that the social representations offered by clinics are designed to attract women to freeze their eggs for social reasons. The content is framed making a relation between this technology and the social obstacles that women face in the society. It is presented as the only solution to overcome social problems. It is argued as a choice for women giving them freedom while other choices imply being captive in the compulsory biological limitations. As our results show, the main arguments focus on a freedom that can be achieved using egg freezing technology for postponing motherhood to be able to do other activities which increase both personal and social level of women.

The result showed the information that is given in relation to egg freezing success rates and the way in which this information has been presented to the clients. This result allowed us to provide a clear insight into the process in which the information in relation to egg freezing success rates has been presented to the clients. In spite of the clinics giving the impression of sharing and communicating accurate success rates, there were no details or explanations of how the rates were calculated.

In conclusion, presenting a high success rate in the web pages of these clinics, in relation to such a complex process, confirms the presence of framed information pre-designed to attract people to make use of their service. 
In general, the presented information on these websites is not enough for an individual to make the right decision. They are designed in a way that can mislead the women in the process of decision making.

These websites must provide reliable and authentic information according to legal and ethical regulation. To be specific, the marketing targeted information should be replaced by informative ethical data which allows women to decide on this technology.
The marketing targeted information should be replaced by informative ethical data which allows women to decide on this technology

Since the number of clinics which are analyzed in this study is limited, it would be necessary to supplement this information with analyzing all the websites of fertility clinics in Spain. It would be also interesting a complement of the women opinion and perception about the information given by these clinics.

As the future line of research, it would be interesting an analysis from a broader perspective to know the perspective of women about representations of maternity in Spain and incorporate the views of medical professionals. Another line of research could be to focus on how the minimum information is delivered by the clinics and to establish a manual of the basic requirements that a website should have, at the content level, about the fertility preservation.

The preservation of fertility is a field that is growing due to the lifestyle of many women and the possibilities that technology offers. The provider of this service must deliver information clearly and accurately. This clear information is difficult to achieve when we talk about a product that is shown according to marketing framing. Therefore, it is important to know them and allow citizens, especially women, to know what their narratives are, so that they can choose more freely.

\section{References}

Argyle, Catrin E.; Harper, Joyce C.; Davies, Melanie C. (2016). “Oocyte cryopreservation: where are we now?”. Human reproduction update, v. 22, n. 4, pp. 440-449.

https://doi.org/10.1093/humupd/dmw007

Bailey, Martha J. (2006). "More power to the pill: The impact of contraceptive freedom on women's life cycle labor supply". The quarterly journal of economics, v. 121, n. 1, pp. 289-320.

https://doi.org/10.1093/qje/121.1.289

Baldwin, Kylie (2016). Ice, ice, baby? A sociological exploration of social egg freezing. PhD Thesis. De Montfort University. Leicester.

http://hdl.handle.net/2086/13109

Blythe, Jim (2009). Key concepts in marketing. Sage. ISBN: 9781847874993

Bartlett, Frederic C. (1932). Remembering: An experimental and social study. Cambridge: Cambridge University.

Cattapan, Alana; Hammond, Kathleen; Haw, Jennie; Tarasoff, Lesley A. (2014). "Breaking the ice: young feminist scholars of reproductive politics reflect on egg freezing". International journal of feminist approaches to bioethics, v. 7, n. 2, pp. $236-247$. https://papers.ssrn.com/sol3/papers.cfm?abstract_id=2801224 https://doi.org/10.3138/ijfab.7.2.0236

D’Angelo, Paul (2002). "News framing as a multiparadigmatic research program: A response to Entman”. Journal of communication, v. 52, n. 4, pp. 870-888.

https://doi.org/10.1111/j.1460-2466.2002.tb02578.x

Donnelly, Laura (2016). "Number of women freezing their eggs triples in just five years". The telegraph, March 23. https://www.telegraph.co.uk/news/2016/03/23/number-of-women-freezing-their-eggs-triples-in-just-five-years

Entman, Robert M. (1993). "Framing: Toward clarification of a fractured paradigm". Journal of communication, v. 43, n. 4, pp. 51-58.

https://doi.org/10.1111/j.1460-2466.1993.tb01304.x

Eurostat (2018). Mean age of women at childbirth and at birth of first child. Eurostat. https://ec.europa.eu/eurostat/tgm/table.do?tab=table\&init=1\&language=en\&pcode=tps00017\&plugin=1

Eysenbach, Gunther; Powell, John; Kuss, Oliver; Sa, Eun-Ryoung (2002). "Empirical studies assessing the quality of health information for consumers on the world wide web: A systematic review". Jama, v. 287, n. 20, pp. 2691-2700. https://doi.org/10.1001/jama.287.20.2691

Gamson, William A. (1989). "News as framing: Comments on Graber". American behavioral scientist, v. 33, n. 2, pp. $157-161$. https://doi.org/10.1177/0002764289033002006

Gill, Rosalind C. (2007). “Critical respect: The difficulties and dilemmas of agency and 'choice' for feminism: A reply to Duits and Van Zoonen". European journal of women's studies, v. 14, n. 1, pp. 69-80.

https://doi.org/10.1177/1350506807072318 
Goffman, Erving (2009). Stigma: Notes on the management of spoiled identity. Simon and Schuster. ISBN: 9781 439188330

Goldin, Claudia (2006). "The quiet revolution that transformed women's employment, education, and family". American economic review, v. 96, n. 2, pp. 1-21.

https://doi.org/10.1257/000282806777212350

Goldman, Eric; Tushnet, Rebecca (2014). "Featuring people in ads”. In: Goldman, Eric; Tushnet, Rebecca (eds). Advertising \& marketing law: Cases and materials. Santa Clara Univ. Legal Studies Research, paper n. 17-14.

https://papers.ssrn.com/sol3/papers.cfm?abstract_id=2479635

Greenfield, Kent (2009). “Corporate law and the rhetoric of choice”. Law \& economics: Toward social justice, v. 24, pp. 61-89. https://lawdigitalcommons.bc.edu/lsfp/239

Harwood, Karey (2009). “Egg freezing: A breakthrough for reproductive autonomy?”. Bioethics, v. 23, n. 1, pp. 39-46. https://doi.org/10.1111/j.1467-8519.2008.00680.x

Hausman, Bernice L. (2008). "Women's liberation and the rhetoric of 'choice' in infant feeding debates". International breastfeeding journal, v. 3, n. 1, pp. 10.

https://doi.org/10.1186/1746-4358-3-10

Hayden, Sara; O’Brien-Hallstein, Lynn (eds.) (2010). Contemplating maternity in an era of choice: Explorations into discourses of reproduction. Lexington Books. ISBN: 9780739138908

Holsti, Ole R. (1969). Content analysis for the social sciences and humanities. MA: Addison-Wesley. ISBN: 9780394349268 Inhorn, Marcia C. (2013). "Women, consider freezing your eggs". CNN.com, April 9.

Instituto Nacional de Estadística (España) (2017). "Número de nacimientos en España 2017, por edad de la madre". Statista. https://es.statista.com/estadisticas/474282/numero-de-nacimientos-en-espana-por-edad-de-la-madre

Jain, Tarun; Barbieri, Robert L. (2005). “Website quality assessment: Mistaking apples for oranges”. Fertility and sterility, v. 83 , n. 3, pp. 545-547.

https://doi.org/10.1016/j.fertnstert.2004.09.030

Kline, Kimberly N. (2006). "A decade of research on health content in the media: the focus on health challenges and sociocultural context and attendant informational and ideological problems". Journal of health communication, v. 11, n. 1, pp. $43-59$. https://doi.org/10.1080/10810730500461067

Koert, Emily; Daniluk, Judith C. (2017). "When time runs out: reconciling permanent childlessness after delayed childbearing". Journal of reproductive and infant psychology, v. 35, n. 4, pp. 342-352.

https://doi.org/10.1080/02646838.2017.1320363

Kotler, Philip (2000). Marketing management: The millennium edition. Prentice-Hall. ISBN: 0536630992 https://www.perspectiva.md/ro/files/biblioteca/Kotler-Marketing\%20Management\%20Millenium\%20Edition.pdf

Kotler, Philip; Keller, Kevin-Lane (2006). Marketing management. 14 $4^{\text {th }}$ ed. New Jersey: Pearson. ISBN: 9780132102926

McCarver, Virginia (2011). "The rhetoric of choice and $21^{\text {st }}$-century feminism: Online conversations about work, family, and Sarah Palin". Women's studies in communication, v. 34, n. 1, pp. 20-41.

https://doi.org/10.1080/07491409.2011.566532

McDonald, Paula K.; Bradley, Lisa M.; Guthrie, Diane (2006). "Challenging the rhetoric of choice in maternal labour-force participation: Preferred versus contracted work hours". Gender, work \& organization, v. 13, n. 5, pp. 470-491. https://doi.org/10.1111/j.1468-0432.2006.00318.x

Meyer, Harriet (2015). “Women 'are being given false hope' over freezing eggs”. The guardian, October 24. https://www.theguardian.com/society/2015/oct/24/women-false-hope-freezing-eggs

Miall, Charlene E. (1985). "Perceptions of informal sanctioning and the stigma of involuntary childlessness". Deviant behavior, v. 6, n. 4, pp. 383-403.

https://doi.org/10.1080/01639625.1985.9967686

Mittal, Banwari (1994). "Public assessment of TV advertising: Faint praise and harsh criticism". Journal of advertising research, v. 34, n. 1, pp. 35-54.

Moyer, Cheryl A.; Vishnu, Leilanya O.; Sonnad, Seema S. (2001). "Providing health information to women: The role of magazines". International journal of technology assessment in health care, v. 17, n. 1, pp. 137-145.

https://doi.org/10.1017/S0266462301104125

Murray, Elizabeth; Lo, Bernard; Pollack, Lance; Donelan, Karen; Catania, Joe; Lee, Ken; Zapert, Kinga; Turne, Rachel (2003). "The impact of health information on the internet on health care and the physician-patient relationship: National 
US survey among 1.050 US physicians". Journal of medical internet research, v. 5, n. 3.

https://doi.org/10.2196/jmir.5.3.e17

Newhouse, Nikki; Lupiáñez-Villanueva, Francisco; Codagnone, Cristiano; Atherton, Helen (2015). "Patient use of email for health care communication purposes across 14 European countries: An analysis of users according to demographic and health-related factors". Journal of medical internet research, v. 17, n. 3, e58.

https://doi.org/10.2196/jmir.3700

Office for National Statistics (UK) (2017). "Average age of mothers at childbirth in the United Kingdom from 2000 to 2017". Statista.

https://www.statista.com/statistics/294590/mother-average-age-of-at-childbirth-england-and-wales

Potter, Jonathan; Wetherell, Margaret (1987). Discourse and social psychology: Beyond attitudes and behaviour. Sage. ISBN: 9780803980563

Press Association (2016). "Number of British women freezing their eggs soars". The guardian, March 23.

https://www.theguardian.com/society/2016/mar/23/number-british-women-freezing-their-eggs-soars-ivf-hfea

Reese, Stephen D.; Grandy Jr., Oscar H.; Grant, August E. (eds.). (2001). Framing public life: Perspectives on media and our understanding of the social world. Routledge. ISBN: 9781410605689

Richards, Sarah-Elizabeth (2013). "Why I froze my eggs (and you should, too)". The Wall Street journal, May 3. https://www.wsj.com/articles/SB10001424127887323628004578458882165244260

Rienzi, Laura; Martinez, F.; Ubaldi, Filippo-Maria; Minasi, Maria-Giulia; lacobelli, Marcello; Tesarik, Jan; Greco, Ermanno (2004). "Polscope analysis of meiotic spindle changes in living metaphase II human oocytes during the freezing and thawing procedures". Human reproduction, v. 19, n. 3, pp. 655-659.

https://doi.org/10.1093/humrep/deh101

SEF (2016). Registro Nacional de Actividad 2016-Registro SEF. Sociedad Española de Fertilidad.

https://www.registrosef.com/index.aspx?ReturnUrl=\%2f\#Anteriores

Shaw, Rachel L.; Giles, David C. (2009). "Motherhood on ice? A media framing analysis of older mothers in the UK news". Psychology and health, v. 24, n. 2, pp. 221-236.

https://doi.org/10.1080/08870440701601625

Smith, Frank A.; Trivax, Geoffrey; Zuehlke, David A.; Lowinger, Paul; Nghiem, Thieu L. (1972). "Health information during a week of television". New England journal of medicine, v. 286, n. 10, pp. 516-520.

https://doi.org/10.1056/NEJM197203092861005

Smith, Gerald E.; Wortzel, Lawrence H. (1997). "Prior knowledge and the effect of suggested frames of reference in advertising". Psychology \& marketing, v. 14, n. 2, pp. 121-143.

https://doi.org/10.1002/(SICI)1520-6793(199703)14:2<121::AID-MAR2>3.0.CO;2-F

Statista (2018). "Global fertility rate from 2006 to 2016". Statista.

https://www.statista.com/statistics/805064/fertility-rate-worldwide

Stoop, Dominic; Maes, Elise; Polyzos, Nikolaos P.; Verheyen, Greta; Tournaye, Herman; Nekkebroeck, Julie (2015). "Does oocyte banking for anticipated gamete exhaustion influence future relational and reproductive choices? A follow-up of bankers and non-bankers". Human reproduction, v. 30, n. 2, pp. 338-344.

https://doi.org/10.1093/humrep/deu317

Teghtsoonian, Katherine (1996). "Promises, promises: 'Choices for women' in Canadian and American child care policy debates". Feminist studies, v. 22, n. 1, pp. 119.

Tuchman, Gaye C. (1978). Making news: A study in the construction of reality. New York: Free Press. ISBN: 9780029329603

Urist, Jacoba (2013). "There's more to life than freezing your eggs". Atlantic, May 4.

https://www.theatlantic.com/health/archive/2013/05/theres-more-to-life-than-freezing-your-eggs/275812

Vallejo, Victoria; Lee, Joseph A.; Schuman, Lisa; Witkin, Georgia; Cervantes, Enrique; Sandler, Benjamin; Copperman, Alan B. (2013). "Social and psychological assessment of women undergoing elective oocyte cryopreservation: a 7-year analysis". Open journal of obstetrics and gynecology, v. 3, n. 1, pp. 1-7.

https://doi.org/10.4236/ojog.2013.31001

Van-Dijk, Teun A. (2013). News as discourse. Routledge. ISBN: 9780805808285

Von-Wolff, Michael; Germeyer, Ariane; Nawroth, Frank (2015). “Fertility preservation for non-medical reasons: Controversial, but increasingly common". Deutsches ärzteblatt international, v. 112, n. 3, pp. 27-32.

https://doi.org/10.3238/arztebl.2015.0027 
Weber, Robert P. (1990). Basic content analysis. Newbury Park, CA: Sage. Quantitative applications in the social sciences, n. 49. ISBN: 9780803938632

Wilkinson, Jack; Vail, Andy; Roberts, Stephen A. (2017). "Direct-to-consumer advertising of success rates for medically assisted reproduction: A review of national clinic websites". BMJ open, v. 7, n. 1, e012218.

https://doi.org/10.1136/bmjopen-2016-012218

Wolf, Mauro (1988). "Communication research and textual analysis: Prospects and problems of theoretical convergence". European journal of communication, v. 3, n. 2, pp. 135-149.

https://doi.org/10.1177/0267323188003002002

\section{Annex}

Hospital Quirón Salud La Coruña

https://www.quironsalud.es/reproduccionasistida/es/quiero-conservar-ovulos-futuro

IVI Alicante

https://ivi.es/tratamientos-reproduccion-asistida/preserva

Unidad de Reproducción Clínica Vistahermosa

https://urvistahermosa.com/es/tratamientos-de-reproduccion-asistida/congelacion-de-ovulos-y-tejido-ovarico

C.H. Torrecárdenas

https://www.reproduccionasistida.org/hospital-torrecardenas

Cerha

https://www.invitrotv.com/fecundacion-in-vitro-fiv

Centro de reproducción asistida clínica Sagrada Familia

https://www.reproduccion-asistida.com

Centro Médico Teknon

http://www.teknon.es/es/unidad-reproduccion-asistida/tecnicas-reproduccion-asistida/vitrificacion-ovulos

Fertilab. Institut Català de Fertilitat

http://fertilab.com/vitrificacion-de-ovocitos

Fundació Puigvert - Hospital de la Santa Creu i Sant Pau

https://www.fundacio-puigvert.es/es/servicios-y-especialistas/areas-de-atencion/reproduccion-asistida

Hospital Clínic de Barcelona

https://www.hospitalclinic.org/es/asistencia/atencion-hospitalaria/ginecologia-obstetricia-y-neonatologia

Institut Dexeus

https://www.de1eus.com/problemas-fertilidad/preservacion-fertilidad

Fundación Jiménez Díaz UTE

https://www.fjd.es/es/cartera-servicios/servicios-materno-infantiles/ginecologia-obstetricia/unidad-reproduccionasistida/tecnicas-tratamientos/ambito-privado

Hospital La Paz

http://www. madrid.org/cs/Satellite?cid=1142401118023\&/anguage=es\&pagename=HospitalLaPaz\%2FPag

Instituto Europeo de Fertilidad

https://www.iefertilidad.com/tratamientos/preservacion-de-la-fertilidad-de-la-mujer

URH García del Real

https://www.urh.es/congelacion-de-ovulos

FIV Valencia

https://www.fiv-valencia.es/tratamientos-fertilidad/preservacion-de-fertilidad

IMER

https://imer.es/tto/congelacion-ovulos

FIV4-Instituto de Reproducción Humana

https://fiv4.es/preservacion-de-la-fertilidad

Clínica Ruber-Centro de Reproducción Madrid, S.L.

https://www.ruberfiv.es/reproduccion-asistida/fecundacion-in-vitro/criopreservacion-de-gametos-ovulos-y-espermatozoidesy-embriones 